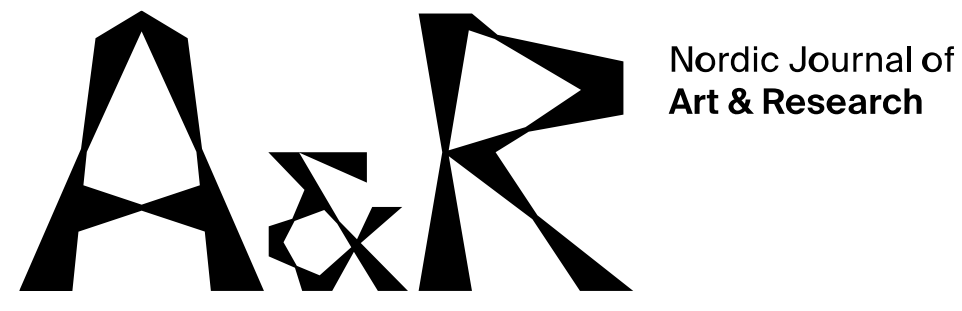

\title{
Exploring Situations Between Art and Pedagogy: The Dance Project Var Vrimmel as an Aesthetic Learning Process with Fourth Graders as Participants
}

\author{
Venke Sortland \& Ida Gudbrandsen ${ }^{1}$ \\ Independent artists
}

\begin{abstract}
This article investigates aesthetic learning processes from the perspective of three dancers working in a school context. It is based on our own experiences from Var Vrimmel - a dance project carried out by the dance group Landing at a Norwegian primary school in 2019, where three dancers were "artists in residence" at a primary school for four weeks. We present three different formats, each with a different relationship between the dancers and the fourth graders participating in the project. Our intention is to outline, describe and discuss how our practice can facilitate aesthetic processes at the intersection between art and education. Our theoretical framework is based on John Dewey's work, particularly his definition of aesthetic experience. Our aim is to contribute to understanding the notion of aesthetic learning processes and broaden perspectives on how artists could work in a school context and the roles they might have.
\end{abstract}

Keywords: Aesthetic learning processes, contemporary dance in schools, art in schools, aesthetic experience, between art and pedagogy, artistic-pedagogical practice.

\footnotetext{
1 venkes@gmail.com, idagudbr@gmail.com

Landing: post@landing.no
} 
Venke Sortland \& Ida Gudbrandsen. Exploring situations between art and pedagogy: The dance project Var Vrimmel.

\section{Introduction}

What does an aesthetic learning process look like from the perspective of a dancer working in a school context? In this article we outline and describe what characterises situations at the intersection between art and education based on our experiences from the dance project Var Vrimmel. In this particular project, where three dancers were "artists in residence" at a primary school for four weeks, we initiated and explored situations that could be categorised as neither a performance nor a dance lesson but rather as something else, something in between. We present three different formats, each with a different relationship between us and the students, where we tried to facilitate these kinds of situations in slightly different ways. All of them consisted of moments which we experienced as situated between what we normally would categorise as either art or pedagogy. These aspects are what we will outline in the article, recognising that this is a work in progress which is to be continued.

An attempt to describe what characterises these situations is relevant first and foremost as a contribution to understanding the notion of aesthetic learning processes (estetiske læreprosesser) ${ }^{2}$, a term used by the Norwegian Ministry of Education and Research for processes that combine artistic and pedagogical dimensions. Second, we find it relevant for broadening perspectives on how artists could work and on what roles they could have in a school context beyond performing completed works (through The Cultural Schoolbag programme) or teaching art in line with a conventional understanding of primary school art education (as in practical aesthetic school subjects that are part of the established curriculum, such as literature, arts and crafts, and music).

The article starts with a brief presentation of the two authors' experience and views on dance and pedagogy, and of their collaborative work in the dance group Landing. We then give a brief account of our methodological perspective in this text and in general. In the next part of the article ("Frames"), we present the foundation for our discussion: the Var Vrimmel project and the theoretical framework we find in John

\footnotetext{
${ }^{2}$ Aesthetic learning processes could be defined as follows: "The student must practice creativity, the ability to create, interact, reflect and communicate, using aesthetic tools. The student should be able to facilitate creative learning through various aesthetic expressions, communication and performances that help to develop students' self-confidence and identity." (Our translation).

(Kunnskapsdepartementet, 2019, p. 32).
} 
Venke Sortland \& Ida Gudbrandsen. Exploring situations between art and pedagogy: The dance project Var Vrimmel.

Dewey's concept of experience. In the last part ("Discussion"), we will discuss our experiences from the Var Vrimmel project.

\section{Landing's heteronomous performative practice}

Landing is a contemporary dance group and production unit run by the authors, Ida Gudbrandsen and Venke Sortland. Through Landing we initiate, produce and carry out dance projects in collaboration with other artists and institutions as a part of the independent performing arts field in Norway. Our dance practice can best be characterised as contemporary dance, where improvisation and choreography are key aspects. In short, we tend to work on more or less clear movement tasks which we solve by improvising rather than by composing steps. And rather than understanding choreography as related solely to the composition of the dancer's movements in time and space, we operate with an "extended choreography" (Østern 2018). According to this term, choreography must be understood as an explorative and critical way of analysing and building up situations, inside or outside the traditional contexts of performing arts.

Landing works on a heteronomous attitude towards, and understanding of, art, meaning that we let our changing surroundings have a defining influence on our artistic work. In both processes and performance situations, we are interested in how structures, contexts and audiences influence the artwork itself as well as us as dancers. Landing understands the artwork as something that is realised through a meeting or interaction between the audience and the artistic expression. This has led us to situate our work outside conventional performance spaces and initiate projects with specific target groups. As a result, we are not necessarily interested in whether or not what we do looks like or is perceived as art to the audience we are addressing. Rather, we have found that knowing that a situation is part of an art project often limits rather than supports the aesthetic experience. Nevertheless, our abilities, knowledge and experience as dancers and choreographers (or rather as artists working on dance and choreography) always inform our starting point.

Since both of us are artists with pedagogical education (Venke holds a master's degree in educational theory and Ida holds a practical-pedagogical bachelor's degree), our practice reaches from teaching to creating and performing dance pieces. In many contexts these activities are perceived as two different fields of practice and knowledge, but in our practice we find that the two sides of our background feed each other in intriguing ways. Furthermore, we are interested in how our aesthetic experiences of working with dance could be shared with schoolchildren through practising together rather than through teaching them. Therefore, we constantly try to 
Venke Sortland \& Ida Gudbrandsen. Exploring situations between art and pedagogy: The dance project Var Vrimmel.

challenge ourselves to initiate projects where we can experiment with forms and formats in between art and pedagogy, performance and educational situations, where we operate with a wider understanding of quality than we find possible through artistic, or pedagogic, quality parameters alone.

\section{Methodological and ethical reflections}

Our practice as dance artists working on social art projects has many similarities with action research as a methodology used in social and pedagogical research. As in action research, we initiate and realise our projects in specific contexts, and we try to situate ourselves as close as possible to the relevant target group for a long period of time. We try to find a starting point that is relevant in and for this particular context, and testing our ideas over and over again with our target group is an important element of the process. Like action research, our practice is also normative in that it seeks to improve, develop or change practice in the direction of something we consider to be of good quality in a specific context. But as is often the case with social art projects like ours, Var Vrimmel was not initially defined as a research project, and the experiences we made were therefore not collected systematically. Thus, written documents, such as reports and notes on reflections on the process, and documentary material in the form of films and photographs, were not produced for research purposes.

In the absence of a large data material, the basis for the discussion in this article is mainly generated through retrospection; i.e., reflections on experiences gained during the process which elaborate and complement any (written) material that exists (Johansen, 2017). However, this presents us with some challenges when it comes to credibility. Does retrospection provide a credible ground for the discussion in this article? Will the reflections on the experiences we gained during the process be too easily be shaped by the argument we want to promote? Rather than rejecting retrospection due to a lack of credibility, however, we would argue that this way of generating a material must be seen in relation to the role and function this article has in our process as a whole. Rather than defining this article as an attempt to see our process from the "outside" by trying to take an observer's perspective on our own practice, we see our reflections on our own experiences as part of the Var Vrimmel project. Furthermore, the discussion must be seen in relation to a goal of improved practice, in this case a practice between art and pedagogy situated within a school context rather than as a way of analysing our practice. This is in line with what Olav Eikeland (2001) describes as action research generating practical knowledge. Unlike action research that generates poetic knowledge based primarily on intervention, i.e., "change social entities of which the knower-actor is not a sharing member", action 
Venke Sortland \& Ida Gudbrandsen. Exploring situations between art and pedagogy: The dance project Var Vrimmel.

research that generates practical knowledge is based on "communities of practice and inquiry, either within the same profession or the same organization, trying to perfect a collective skill or the understanding of practically shared, common points of reference" (Eikeland, 2001, p. 147). Since we are primarily interested in exploring and improving our own practice, the goal of the Var Vrimmel project was to generate practical knowledge; knowledge about and for our practice. Thus, retrospection should be seen as a crucial part of the process itself, and the descriptions we use when reflecting on our experiences must be seen as examples that provide us with a starting point for discussion rather than empirical data.

The distinction between action research that generates practical versus poetical knowledge is also important when it comes to ethical research perspectives. If we focused on the students' reactions, as is the case in action research generating poetic knowledge, the examples from Var Vrimmel would be problematic without a thorough reflection on who has the power to define what is experienced and on what measures are taken to reduce this power by, for example, including students' voices in the form of interviews. But since it is our own practice we try to explore, challenge and improve, using discussion as a tool, it should be implicit that we describe and speak about our own experiences, not those of the students. We have nevertheless chosen to remove the names of places, schools, staff and students, as this information has no relevance to the discussion.

\section{Frames: Var Vrimmel as an aesthetic learning process}

\section{The Var Vrimmel project}

In this section we will present the basis of our discussion: the dance project Var Vrimmel and the notion of aesthetic experience that we find in John Dewey's work. Var Vrimmel was carried out by Landing at a Norwegian primary school in January and February 2019. The project was initiated by a regional production unit, an interest organisation for dance, and the local centre for culture and education, and received support from Arts Council Norway. In collaboration with the school, Landing was invited to create a project at the intersection of art and pedagogy, with and for students in the fourth grade, where citizenship should be the overall theme. Var Vrimmel took place as a kind of artistic residency where we, the authors of this article, together with dancer Maja Roel, moved our artistic practice into a primary school. Our artistic interest was intertwined with our pedagogical work, meaning that we wanted to explore how working within a pedagogical context and with the students would influence our artistic practice, and to create situations where we could 
Venke Sortland \& Ida Gudbrandsen. Exploring situations between art and pedagogy: The dance project Var Vrimmel.

include the students in our artistic work and/or use our artistic methods and skills in teaching situations.

In the initial contact with the school before the residency period, we agreed with the teachers, on a theme for the project: democracy and citizenship. We emphasised a processual understanding of democracy as a practice that must be maintained through participation. By involving the students in working on this through contemporary dance, we had an understanding that they would have the potential to experience it as a bodily and sensory experience; that being received when falling, providing a secure base on which a fellow student can climb or joining a group and working on the same physical task, but solving it individually, are experiences of democracy that can have a powerful impact.

Var Vrimmel lasted four weeks, and during that time we were present in the school building throughout the whole school day. In addition to the work we did together with the fourth graders, we (the three dancers) had our own daily dance routine that took place in different parts of the school area. And rather than work towards a large-scale final performance, we focused on the process, and created small performance-like situations several times a week. In these situations, the students were sometimes performers together with us, other times we performed small improvisations for them.

\section{Theoretical perspective: Dewey's notion of experience}

As mentioned in the introduction, the aim of Var Vrimmel was to initiate aesthetic learning processes. Aesthetic learning processes is a notion that is often used in the field of pedagogy and is highlighted in official documents as an important aspect in all school subjects (Kunnskapsdepartementet, 2019). Nonetheless, the term is perceived to be rather vague, and is used in different ways in different settings. ${ }^{3}$ As stated in the introduction, we want to explore the field of aesthetic learning processes as something in between conventional formats such as dance lessons and performances. This means that we are not interested in the pedagogical potential in a dance performance, nor the aesthetic dimensions found in conventional pedagogical formats. Rather, we are drawn towards formats and roles which are more unclear, but which at the same time provide the students with safe and/or supportive boundaries. In our heteronomous art practice, as well as in this article, we find the

\footnotetext{
3 The vagueness and confusion associated with the term was the theme of a seminar initiated by DiS (Dans I Skolen) in November 2019: https://dramaogteater.no/debatt-hva-er-estetiske-laereprosesser/
} 
Venke Sortland \& Ida Gudbrandsen. Exploring situations between art and pedagogy: The dance project Var Vrimmel.

American philosopher and educator John Dewey's notion of aesthetic experience helpful in understanding what aesthetic learning processes could be. According to Dewey (2005), aesthetic experience can be understood as the effect an art expression potentially can create in interaction with an individual; a period of heightened attention that has value in itself which leads to an educational process, a growth or transformation, and which thus forms the basis for new deeper and broader experiences. For Dewey (2005) an aesthetic experience is the ideal form of experience because it has no goal beyond itself. Furthermore, it is in the aesthetic experience that the interaction between the environment and the individual has the best quality.

One could ask whether Dewey's thinking is relevant when discussing contemporary pedagogical and artistic practice and challenges. Even though his descriptions of artworks and educational settings are clearly outdated, we still find his notion of experience and the anti-dualism that underlines his work - where he opposes clear distinctions between body and mind, praxis and theory - highly relevant. When using Dewey's work as a theoretical perspective in this article and in our practice in general, we try to narrow down the core principles while at the same time trying to relate (and attune) them to our experiences as artists and teachers. Nevertheless (or rather because of this), in our work we apply Dewey's notion of aesthetic experience to a wider spectrum of situations and practice than he himself did (in his work Art as Experience (2005), situations in between performance and dance lesson, where the students participate in the situations together with us. Support for this widening of the term "aesthetic experience" is derived from the American neo-pragmatic philosopher Richard Shusterman. According to Shusterman (2000), an individual can have an equally qualified aesthetic experience from a somatic practice or from different movement practices (for example, yoga or tai chi), as from an artistic expression in the conventional understanding of the notion. Shusterman thus opens for further exploration of what an "artistic expression", to use Dewey's term, could be.

At the same time, the experiences and processes we explore in this article are not necessarily "purely" aesthetic, but rather lie at the intersection between art and education. Dewey defines learning experiences as somewhat different from aesthetic experiences, even though they partly overlap and have no sharp boundaries. For Dewey, these types of experiences are different first and foremost in their anticipated outcome; a learning experience results in new skills or knowledge, while in the aesthetic experience the experience itself is the outcome. One could of course add several other aspects that separate education from art. One example we find relevant in this context is the art historian Claire Bishop's argument (2000) that the 
Venke Sortland \& Ida Gudbrandsen. Exploring situations between art and pedagogy: The dance project Var Vrimmel.

relationship between the artist and the student is different in an art context compared with an educational context, because in the former you also have one or another form of external audience to relate to. In projects like Var Vrimmel, where students and teachers are participants, working together with the artists, the external audience one has to relate to in an art context does not exist. But at the same time, playing at being an audience for each other, performing for one's classmates and teacher or for other groups of students in one's school, could help children find a mode and a concentration which in turn shifts the orientation of the experience from a learning outcome towards an experience in itself. It is nevertheless worth noting that Dewey's definition of experience, whether it be aesthetic or not, is founded on an educational process understood as a process of transformation with a subsequent growth. And in Var Vrimmel we were looking for both aesthetic and educational outcomes, and for them to arise simultaneously. This, we think, is in line with the type of processes and situations that are outlined in the notion of aesthetic learning processes. We are aware that, in this aspect, we choose an open, relational and dynamic understanding of how Dewey sees the borders between art and pedagogy. 4

No matter what educational or aesthetic outcomes the experience or process should have, it is important to underline that we, as artists or educators, can prepare and facilitate for them but we can never produce them with certainty; that happens to the individuals through interaction or co-creation (Dewey, 2005). This makes it no less important to ask how to facilitate these processes and experiences. We find this important when we do performances, but even more so when we want to create and explore situations in between the aesthetic and the educational, when we are interested in having an open understanding of both art and pedagogy, when we are experimenting with forms and formats outside performances and dance lessons, and when the interaction that constitutes the experience can involve everything from being an immersed spectator to actively participating in creating the artistic expression together with us.

\section{Discussion: Situations between pedagogy and art}

In this section we will use three examples from Var Vrimmel to outline and describe aspects which we think characterise situations in between art and pedagogy. First, we introduce our morning warm-up sessions with the students, the pedagogical

\footnotetext{
${ }^{4}$ Other pedagogical thinkers, such as Hansjörg Hohr, choose to understand Dewey's division between art and pedagogy as less dynamic (Hohr, 2012).
} 
Venke Sortland \& Ida Gudbrandsen. Exploring situations between art and pedagogy: The dance project Var Vrimmel.

format for which was the most conventional used in the project, one where we, the dancers, clearly took the lead. In this situation we tried to open up for and focus on the students' experience within a conventional pedagogical format where we instructed them. The second situation, the body chain, is from a format where we tried to create a task that made us and the students practice together, where we, in other words, tried to make the distance between the different roles (student and teacher) less prominent (without thinking that they could be totally levelled), and to minimise the need for oral instruction. The third situation is one where we were close to an art format (performance), where we worked on solo and group improvisations in the common areas of the school, and tried to allow the students to decide for themselves whether, how and when they wanted to relate to us and what we did, either as audience, directors or co-performers.

As a framework for discussing the situations, we will also present two parameters, namely interest/resistance and strong/weak, based on Dewey's notion of aesthetic experience.

\section{The parameter of resistance/interest}

Dewey (1934/2005) writes that an experience begins with a sensation of resistance from one's surroundings that awakens the individual's interest. This dynamic between resistance and interest produces the elation and the emotional state an aesthetic experience can be said to be. The experience reaches its end when the resistance fades and the interest, accordingly, decreases (Dewey, 1934/2005). The idea that the dynamic between the individual's interest and the resistance of the environment is crucial in creating an experience becomes clear in Dewey's definition of pedagogy as a weighing between the child and the curriculum, or in other words as a matter of balancing the student's world of experience against the scientific disciplines' world (1902/2001). The same principle can be said to apply to an audience member's encounters with artistic expression, but here the emphasis between interest and resistance must be understood as a balance between the artists professional perspectives and the individual's experiential background. Therefore, we must, according to Dewey (1934/2005), meet the target group on their own terms, we must open ourselves to their interests, how they understand the world and their ways of being. At the same time we must give the interaction a specific direction by introducing a material, a content, an artistic resistance. In other words, when we see the relationship between the audience and the artistic expression as constitutive, an ongoing challenge that follows is to balance a specialised artistic focus against an understanding of the target group's perspective and their earlier experiences. 
Venke Sortland \& Ida Gudbrandsen. Exploring situations between art and pedagogy: The dance project Var Vrimmel.

\section{The parameter of weak/strong direction}

In the process of writing this article using the parameter of interest/resistance, it became clear to us that it did not fully cover the challenges we experienced. We therefore added a supplementary parameter, inspired by Dewey's notion of experience. To better show what the ideal quality of an experience should be, Dewey (1934/2005) makes the reader picture the difference between an interaction (between the individual and the surroundings) that is too purposeful and targetoriented, too oriented towards action, and one that is without connection and/or almost meaningless, too oriented towards perception. According to Dewey, the interaction should ideally be in between these two, neither too strong nor too weak, if the goal is to produce an aesthetic experience. This resonates with how we work both artistically and pedagogically. For as we, on the one hand, are interested in the potential we believe art holds to facilitate something we cannot (and/or should not) control - a potential for something different to unfold - we experience and acknowledge that a situation that is too open, where whatever can happen or everything could be the right answer, is often uninteresting and non-motivating for students (and for audiences in general). In this article we refer to this parameter as situations where we tentatively impose a weaker or stronger direction, and thereby facilitate a more purposeful or more meaningless interaction. As already mentioned, artists and educators can never (nor should they) guarantee that the situations they initiate produce the effect they hope for in the audience or the students. We still believe that being specific when formulating our intent for the interaction we initiate makes it easier for the students to relate to and to become interested in.

\section{Morning warm-up sessions: Aesthetic learning processes in a dance-lesson format?}

The first situation we want to reflect upon is the one which for us is the more conventional in a school context: joint physical warm-up sessions every morning. This was our daily ritual with the fourth graders. Here we tried to develop the students' bodily awareness and possibilities for movement. Our aim was to present the students with basic knowledge in dance through exercises which at the same time challenged them to take care of each other through working together. A common thought when working creatively or with creative dance is that "everyone can dance, they just forgot how to do it", and that contemporary dance is therefore quite intuitive for children. We do not believe in this, nor do we experience it when meeting children. The task "just create a movement" must be learned or developed through several experiences, in the same way as other skills. Furthermore, in most schools in 
Venke Sortland \& Ida Gudbrandsen. Exploring situations between art and pedagogy: The dance project Var Vrimmel.

Norway, dance is not an important part of the curriculum, and teachers seldom have the necessary competence in dance (Rustad, 2017).

Each morning session started with a massage, where the students worked together in pairs. The students had to listen to their partner through the oral and physical reactions they received on the massage they gave. The massage also became an opening and transition into more "advanced" partner work, with "giving and taking weight", providing physical support for one or more of the other students, or with different tasks and games where one should share physical contact points with another person. The morning sessions usually ended with a relaxation part, where the students were asked to lie completely still on the floor and relax their whole body. This exercise had two purposes: to provide an experience of relaxing and sinking down through the floor (a bodily experience and skill) and to concentrate on their own bodies without disturbing the person next to them, and thereby respect and make space for their fellow students' experiences (which could be connected to the theme of the project, i.e. democracy and citizenship).

Through the morning sessions we tried to facilitate an aesthetic learning process using a format the students were familiar with. We wanted to see if we could expand the format to include situations where the students' experiences were in the foreground and our instructions in the background. But, as any experienced teacher might have anticipated, it was perhaps easy for the students to act the way they usually did in other teaching situations, since this format and these roles (we were instructing while they were doing/solving the tasks) are very familiar to the students in their everyday lives. As a result, we had to spend time on aspects we find problematic with conventional teaching formats for dance education: instructing and disciplining rather than facilitating creativity and activity. We began to act more and more like conventional teachers and less like artists-teachers inviting the students into our artistic and creative processes.

Seeing this situation through Dewey's concept of aesthetic experience and the parameter of resistance/interest, we could say that lack of resistance in these formats probably made it hard(er) for the students to be interested in what we offered in the morning sessions. At the same time, even though the format - and teaching style - of the morning sessions were very familiar to the students, the content - contemporary dance - was foreign to most of them, meaning that the resistance in the content was perhaps too strong. In relation to both the format and the content, we lacked a balance between the familiar and the challenging, between interest and resistance which created a more challenging and less engaging situation, not only for the 
Venke Sortland \& Ida Gudbrandsen. Exploring situations between art and pedagogy: The dance project Var Vrimmel.

students but also for us. When examining the morning sessions in retrospect, it is clear that we did not offer movements and tasks which we believe in artistically, or which we use when making art. Rather, we presented movement tasks which generally are considered to be basic knowledge when beginning to learn contemporary dance.

When looking at the morning sessions through the parameter of strong and weak direction, it is clear to us that the content we introduced had a very strong purpose: to give the fourth graders basic knowledge about contemporary dance. We presented this through oral and physical instruction, without allowing the students to relate to the material in their own way. The direction we inserted was, in other words, too strong, leaving inadequate space for the students' own imagination and creativity.

Nevertheless, looking back on these daily sessions, we see that we probably managed to give the students a good introduction to working on contemporary dance, something we consider to be an important factor in creating situations in between art and pedagogy later on in the project. We also found it interesting, on a conceptual level, to situate such dance lessons in the entrance hall of the school - as if we, through this, were making the kind of bodily experiences and knowledge that we promoted through the project more visible on a physical and discursive level, also for the students and teachers that were not directly involved in the project. However, these more conceptual aspects of the project were probably out of reach for the students.

One of the aspects that became clear from the morning sessions was the importance of finding a balance between the known and easily accessible on the one hand and the unknown and more demanding on the other. This applied not only to the students but also to us. In other words, when facilitating situations in between art and pedagogy, we find it important that we teach and share something we find artistically interesting, in such a way that we are genuinely curious about how the students will receive, relate to and use the tasks we give them, at the same time ensuring that the students perceive the tasks as relevant and doable to them.

\section{The body chain: Teaching through practicing together}

The experiences from the morning sessions led us to explore how we could move away from more conventional pedagogical formats and roles - not only in the way we behaved, but also in the exercises we suggested - and try to lead using a minimum of oral instruction. This made us look for and try out exercises where we had to listen and synchronise as a large group and be involved on the same level as the students. 
Venke Sortland \& Ida Gudbrandsen. Exploring situations between art and pedagogy: The dance project Var Vrimmel.

One example of this was walking as slowly as possible from the outer edges of a space towards the centre, and paying attention to each other to make sure that we all met in the centre at the same time. We initiated many such situations with smaller or bigger groups of fourth graders in the common areas of the school, both indoors and outdoors, and although we were clearly leading them by initiating and knowing what the exercises were about, we felt closer to our practice as performers than as teachers.

One task where this became particularly clear was when we worked with what we called the body chain. In this exercise, each student created a position, the next student connected to that position and created his/her own position, and in this way the chain extended through the surroundings. When all the students were part of the chain, the student who made the first position ran to the front and created a new position, and the chain moved forward. We did this body chain as a happening that included all the students and teachers in the entire school. The respective student groups created a chain that slowly made its way through the school building, lasting for 20 minutes.

Several aspects of this situation are worth reflecting on when looking for what categorises situations in between art and pedagogy. First, one of the reasons we could make the distance between the different roles (student and teacher) less prominent when practising the body chain was that the fourth graders had already worked on this particular task under our guidance several times and in many different rooms earlier in the process. When the whole school was preparing for the happening, it was the fourth graders that visited each student group and taught them how the body chain worked. These students demonstrated a sense of ownership to it, adding their own personal touches to their explanations and demonstrations. Seeing the students' involvement and engagement, we saw no need to take a visible role as leaders or instructors. The result of the training and gradual sense of ownership led to a situation where we found we could practice together with the students, and where we could be "in the moment" in a way that resembles or is close to the way in which we are present on stage as performers, where we fully invest in the tasks and the execution of them as practitioners, not as guides or instructors. We see this type of concentration and presence as an important part of practising contemporary dance (at least as important as technical brilliance). A positive spiral effect may also have been in play here: the students had gained ownership to the task, which allowed us to invest in it as performers, a concentration which, in turn, would affect or even pass on to the students. All in all, we felt that in this situation we began to see a blurring of 
Venke Sortland \& Ida Gudbrandsen. Exploring situations between art and pedagogy: The dance project Var Vrimmel.

the boundaries between the pedagogical and the aesthetic dimensions of the project; the format felt closer to a performance.

The situation had another, related, effect. In this situation, the students were both performers and audience. This challenged the students to not only be aware of what they themselves were doing, but also of what was happening around them. The embodied listening skills they had practiced in the morning sessions (working together through for example giving each other massages and/or leaning weight into each other in pairs), were expanding, to include listening to their surroundings as well. While the students worked together to hold their positions as part of the chain of their own student group, they seemed to grow increasingly aware of having an outside audience to relate to (even if it only consisted of their teachers and fellow students) when doing this exercise outside their classroom. Furthermore, it seemed to us as if this two-way listening (at this moment in the process) actually made it easier for the students to invest in the work, perhaps because the group, when confronted with other individuals, became clearer to them. We find this type of twoway listening, to each other and to the surroundings, to be a key skill in our practice as contemporary dancers.

If we turn to the parameter of strong and weak direction, in the body chain the students were given more freedom to solve the task in the way they wanted, than in the morning sessions. We find that allowing such freedom is an important aspect of working on improvisation within contemporary dance, as it creates ownership of the movements and choices, and cultivates creativity. At the same time, the freedom to make one's own choices took place within strict limits, and we could easily foresee more or less what the outcome of the tasks would be.

Looking at the body chain from the perspective of the parameter of interest and resistance, we found this situation more balanced than what was the case in the morning sessions, maybe because the task was also formulated somewhat like a game, a game the students learned relatively fast and liked to play. At the same time, the game differed, in our experience, from what the students themselves played in their free time, as it challenged aspects such as their two-ways listening skills (as described above).

Characteristics of the situation with the body chain could be summed up as follows: the students took ownership of the task and how to solve it, we were teaching through practising together with the students rather than instructing them. We avoided controlling the students, and instead gave them the freedom to relate to and 
Venke Sortland \& Ida Gudbrandsen. Exploring situations between art and pedagogy: The dance project Var Vrimmel.

engage with the situation as they wanted to, though with clear direction from us. All in all, the body chain became an example of a situation where we actually felt we managed to work in between the artistic and pedagogical fields. Looking back on the performance which we, the whole school, performed together, we would even go so far as to say that this situation created a potential for aesthetic experience.

\section{Our daily dance practice: Facilitating multiple ways of participating}

Every day, the morning sessions with the students were followed by an hour where we, the three dancers, worked on movement material on our own. We gave ourselves and each other improvisational tasks and worked on them alone or as a trio, using different parts of the common areas in the school building as sites. We were in connection with our surroundings, wanting them to influence our improvisations, meaning that we met the context quite openly, without bringing too much to the table ourselves. During these sessions, most of the students were in their classrooms and were only able to catch glimpses of us through windows or on their way to the toilet or the locker rooms. Still, we considered this daily dance routine to be kind of a performance, and our way of being in it resembled the way we are on stage.

Initially the students often ignored us during these sessions, and did not seem to want to engage with us. But after working on our solos in different sites around the school building for many days, the students suddenly began to interact with us on their way in and out of the classrooms or while in the locker rooms. Some of them would stop and watch, some actually started moving together with us, and some would ask us what we were doing while we were doing it. The format of our improvisations made it possible for the students to interact with us in less structured ways than what would be possible in a dance lesson or performance. It also allowed students to interact with us in several different ways at the same time. In these situations, we let go of our control, and trusted that the students had enough information and interest to interact in ways that were not necessarily predictable or a result of their habitual way of interacting with each other and their surroundings, such as tossing themselves into a wall in the hallway together with one of us, or becoming part of a tight swarm of students and dancers moving slowly through the schoolyard. These eruptive meetings were almost impossible to calculate or plan, but to us they had great potential, and the fact that they occurred from time to time made us continue to explore and discuss them throughout the project.

If we look at these situations from the perspective of the parameter of resistance and interest, it is easy to assume that they give the students a relatively high resistance. 
Venke Sortland \& Ida Gudbrandsen. Exploring situations between art and pedagogy: The dance project Var Vrimmel.

We are adults who behave in ways adults do not tend to in a school context, through an art form with aesthetics and conventions that are unknown to most of the students. It was, in other words, probably hard for the students to "understand" (or rather decipher) what we are doing and why. At the same time, we imagine that because this takes place in a familiar place (their own school) and over a relatively long period of time, the resistance will gradually be reduced. This correlated with our experience. It is also worth noting that the improvisations consisted of movements such as crawling on the floor, lying under benches or in lockers, jumping and falling, all things the students (can) do with their own bodies, and that were related and relevant to their world. In this situation there seemed to be a better balance between resistance and interest than we first feared.

From the perspective of strong and weak direction, it is obvious that we could have had clearer goals, concepts and directions for the artistic work we did in these sessions. On the other hand, we did not find that the students saw it as random or meaningless. This might have something to do with the repetition and persistence in these situations, working on the same tasks in the same places over time, repeating the situation (almost) every day of the residency. It might also have something to do with how we were present in these situations: we related openly with the students who passed us, and answered honestly when they asked us what we were doing, for example: "I'm pretending to be a rag that is being pushed down the hallway."

From these experiences we derive that when moving with and next to the students, it seems essential that we are fully invested as performers and dancers while also able to take in and relate to their impulses. This is in line with the argument promoted by Lisa Nagel and Lise Hovik (2018) that formats allowing for different types of contracts with the audience also demand different performer skills. Allowing the audience to be physically present and to interact with you on stage demands different skills from those required when communicating with an audience seated in an auditorium. Another aspect we find interesting in these situations, is that they unfold in ways we cannot really predict (which challenges us to take a certain risk), unlike the morning sessions and the body chain.

\section{Summary and conclusion}

The aim of this article has been to explore what an aesthetic learning process might look like by reflecting on our experiences from Var Vrimmel, a dance project carried out by the dance group Landing at a Norwegian primary school in the first two months of 2019. For our theoretical framework, we used John Dewey and his 
Venke Sortland \& Ida Gudbrandsen. Exploring situations between art and pedagogy: The dance project Var Vrimmel.

definition of aesthetic experience, as we considered it a relevant and interesting approach to understanding the notion of aesthetic learning processes.

We presented three different formats, each with a different relationship between us and the students, which we worked on in the Var Vrimmel project, namely the morning sessions with the students, the body chain, and our daily dance practice. We reflected on these formats, introducing the parameters of resistance/interest and what we have called weak/strong direction, with the intent of outlining and describing some of the aspects we consider characteristic of situations in between pedagogy and art. In the list that follows, we focus on how, through our artistic-pedagogical practice, we can facilitate for such processes. The list cannot, however, in any way be considered exhaustive, but rather a work in progress that will keep on growing and become more specific:

In facilitating for situations in between art and pedagogy, we should:

- make sure that the content, movement tasks and formats are artistically interesting to us and relevant to the students.

- find ways to be fully invested as performers and dancers, and at the same time be able to take in and relate to the students' impulses.

- practice together with the students, working on the same task and finding ways to lead the explorations with a minimum of oral instruction.

- give the students possibilities to gain ownership of the dance they do.

- avoid controlling the students' reactions through predefined roles, and instead give them the freedom to relate to, and engage with, the situation in multiple ways.

- allow situations to develop in ways we cannot really predict (which challenge us to take certain risks).

Even though the list is a work in progress, it could be seen as an example of how an aesthetic learning process could unfold and what aspects could be at play in such processes. One could say that these aspects are characteristic of such processual and explorative educational practices which Dewey represents more generally. But 
Venke Sortland \& Ida Gudbrandsen. Exploring situations between art and pedagogy: The dance project Var Vrimmel.

what makes them specific for an aesthetic learning process is, to our mind, that we base our work in an artistic practice and knowledge. In a future version of Var Vrimmel, we hope to find other ways to facilitate these situations, grounded in our practice and methods as dancers, allowing more risk and trying formats less familiar to us and the students. In extension of the aesthetic learning processes offered to the students through the practical aesthetic school subjects and The Cultural Schoolbag programme, we consider it important that artists contribute to exploring how to facilitate processes in between art and pedagogy and what these kinds of processes can produce. Through relatively short but intense "residencies" in schools, like the one we had, artists could also have a positive influence on the daily pedagogical work through boosting the aesthetic dimensions of an interdisciplinary working period (where the students work on one theme, such as democracy and citizenship), and inspire teachers to explore new teaching methods and formats. In a pedagogical context, exploring new types of formats for facilitating aesthetic learning processes could in the long run have a positive effect on artists' work towards better integration of artistic practice in society and a less elitist understanding of art.

As we mentioned in the introduction, critical reflection on our experiences is an integrated part of the way we work as artists and educators. This article is therefore a continuation of an already existing discussion on the Var Vrimmel project. At the same time, the writing process has challenged us to use theoretical frames, concepts and parameters like those we derive from Dewey in a more systemised way, and thus has given us the possibility to gain a more detailed perspective and deeper understanding. We hope and believe that the discussion will have value in the practice it generates, or in other words, in its potential for initiating more effective and/or different aesthetic learning processes, as well as in demonstrating what an aesthetic learning process could look like and open up this subject to further discussion outside the professional dance community.

\section{About the authors}

Venke Marie Sortland is an independent dancer, choreographer and writer, based in Oslo. She has her artistic training from Skolen for Samtidsdans in Oslo (now Høyskolen for Dansekunst) and has studied pedagogy and aesthetics at the University of Oslo. Sortland does her own artistic work with the constellations Landing and Bøler Samvirkelag. She is currently working as a program producer for 
Venke Sortland \& Ida Gudbrandsen. Exploring situations between art and pedagogy: The dance project Var Vrimmel.

children and youth at MUNCH and as a dance-consultant for Norsk Shakespearetidsskrift (The Norwegian Shakespeare Journal).

Ida Gudbrandsen works as an independent dancer, and has developed artistic projects with the constellations Landing, Supernova and Bøler Samvirkelag. She has a degree in dance and pedagogy from the Norwegian University College of Dance (Den Norske Ballethøyskole, now Norges Dansehøyskole), with a specialization in contemporary dance and cultural management. Gudbrandsen has been employed by the Alliance for Actors and Dancers (Skuespiller-og danseralliansen) since 2017.

\section{References}

Bishop, C. (2012). Artificial Hells: Participatory Art and the Politics of Spectatorship. London/New York: Verso.

Dewey, J. (2001). Barnet og læreplanen. In E. L. Dale (Eds.), Om utdanning. Klassiske tekster (pp. 23-40). Oslo: Gyldendal Akademisk.

Dewey, J. (2000). Skapende demokrati - oppgaven foran oss. In S. Vaage (Eds.), Utdanning til demokrati. Barnet, skolen og den nye pedagogikk. John Dewey i utvalg (pp. 263-269). Oslo: Abstrakt forlag.

Dewey, J. (2005). Art as Experience. London: Penguin Books.

Eikeland, O. (2000). Action Research as the Hidden Curriculum of the Western Tradition. In P. Reason (Eds.), Handbook of Action Research: Participative Inquiry and Practice (pp. 145-155). Thousand Oaks: SAGE Publications Ltd.

Hohr. H. (2012). The Concept of Experience by John Dewey Revisited: Conceiving, Feeling and "Enliving". Studies in Philosophy and Education, 32, 25-38. https://link.springer.com/article/10.1007/s11217-012-9330-7

Johansen, J. B. (2017). Retrospeksjon som vitenskapelig forskningsmetode. Utdanningsforskning.no.

https://utdanningsforskning.no/artikler/2017/retrospeksjon-som-vitenskapeligforskningsmetode/

Kunnskapsdepartementet. (2019). Skaperglede, engasjement og utforskertrang. Praktisk og estetisk innhold i barnehage, skole og lærerutdanning. https://www.regjeringen.no/contentassets/c8bbb637891443fea7971ba8e936b ca4/skaperglede-engasjement--og-utforskertrang.pdf

Nagel, L. \& L. Hovik (2018). Interaktiv scenekunst for barn - tyranni eller magi? In L. Nagel, Kunst for barn som hendelser. En kritisk diskusjon av analytiske perspektiver i kunst for barn med eksempler fra scenekunst, bildebøker og bildebokapper [Doctoral dissertation, University of Oslo]. 
Venke Sortland \& Ida Gudbrandsen. Exploring situations between art and pedagogy: The dance project Var Vrimmel.

Rustad, H. (2011). Dans og kroppsøvingsfaget. In Journal for Research in Arts and SportsEducation, Vol. 1, 2017 (pp. 61-74). https://jased.net/index.php/jased/article/view/576

Shusterman, R. (2000). Pragmatist Aesthetics: Living Beauty, Rethinking Art. Rowman \& Littlefield.

Østern, T. P. (2018). Choreographic-Pedagogical Entanglements. In S. Holte, A-C. Kongsness and V. Sortland (Eds), KOREOGRAFI 2018.

https://choreography.no/index.html 